\title{
Video Data Analysis for Tracing Emotional Aspects of Collaborative Design and Making Processes
}

\author{
Tiina Paavola, Kaiju Kangas, Sirpa Kokko, Sini Riikonen, Varpu Mehto, \\ Kai Hakkarainen and Pirita Seitamaa-Hakkarainen
}

\begin{abstract}
The purpose of the article is to introduce a systematic, three-level video analysis method for tracing the emotional aspects of a collaborative design and making process. Maker-centred learning can evoke strong emotions affecting students' motivation because it involves them in externalising their ideas through conceptual, visual and material artefacts. For analysing longitudinal collaborative processes, we developed the visual Making-Process-Rug video analysis method, which enables tracing materially mediated verbal and embodied making processes. We provide examples of the method using data, where a team of seventh-grade students performing regular schoolwork were engaged in using traditional and digital fabrication technologies for inventing, designing, and making artefacts. Taking a case study perspective, we focus on a team of four students who worked on a smart product project. We analysed video recordings from the team's 11 hours of design and making sessions on three levels: macro, intermediate and micro. The benefit of the three-level method is that it allows simultaneous analysis of social-discursive and materially embodied aspects of activities. It also enables analysing large samples of video data systematically, and focusing on both micro-level and macro-level perspectives of activity. The method for identifying emotions from video data has potential for educational research on various fields, however, the culture-specific expressions and interpretations of emotions require special attention when developing the method further.
\end{abstract}

Keywords: basic education, collaborative process, emotional expression, Making-Process-Rug, sociomateriality, video analysis method

\section{Introduction}

Video research is established in the area of researching crafts and craft education. It has been widely used in craft settings to capture the ongoing process of designing and making artefacts. Video research has been used for various purposes: to analyse working in the craft classroom (Johansson, 2002; 2011) and to study verbal and nonverbal interactions between students and the teacher (Andersson, 2019; Koskinen et al., 2015). Also, studies related to teaching manual skills (Ekström, et., al. 2009; see also Ekström, 2012) and the transformation of physical materials into artefacts (Illum \& Johansson, 2012) have relied on video data. Furthermore, the analysis of interactions within a small team (Kangas et al. 2013; Lahti et al., 2016) and teachers' longitudinal orchestration on technology-enhanced learning (Viilo et al., 2018) are based on video research. Video research has also been used to explore early childhood craft education as well as pre-schoolers' work with materials and tools (Carlsen, 2015; Yliverronen et al., 2018). According to Illum and Johansson (2012), analysing the teaching and learning of crafts in the classroom reveals various hidden means of interaction and multidimensional aspects related to learning craft skills. However, Westerlund (2015) recognized that it is challenging to draw conclusions from the students' emotional response to teaching and learning by observing the classroom situations. In the current article, we present how we have developed a video data analysis method in studying craft education in basic education. More particularly, our focus is on the systematic video analysis method that was used for tracing the emotional aspects of students' collaborative design and making process.

Research on the learning sciences has combined video research with the intensive study of classroom teaching and learning situations (Derry et al., 2010). Video recording of craft activities has been 
recognized as a relevant method for documenting learning. The method has been found to be efficient in contexts where the aim is to capture learning as an interactive sociocultural phenomenon, especially from the perspectives of collaborative talk and embodied actions (Anderson, 2019; Streeck et al., 2011; Knoblauch et al., 2009). It has been most useful for processing the data, where the main focus of the analysis is on the design and making process that unfolds over time. Observations of embodied actions, as well as tracking the active and dynamic role of materiality, would be unmanageable without utilizing video technologies.

In Finland, craft science is a specific academic field concentrating on craft research (Kokko et al., 2020). Within this field, the video data method has been used in a range of craft research: for capturing experiential knowledge of tactile augmentation and for analysing embodied ways of making sense through making with the hands (Groth et al., 2015). In addition, the video data method was used in a study focusing on collaborative sketching (Härkki et al., 2018a) and the use of sketching and gesturing in collaborative designing (Härkki et al 2018b). These examples reveal that video research provides possibilities in multiple craft settings, where learning is observable and accountable, embedded in interactive activity, and mediated by various tools and materials. The rapid development of light and easy-to-use video cameras (Derry et al., 2010) and the availability of new tools and methods for data analysis have increased the use of the video method (Reiman, 2009). Indeed, videoing is an effortless and efficient method for collecting large amounts of data. However, the methods for video data analyses vary considerably and have not received much attention in the research literature.

During several research projects and after collecting more than 500 hours of making-process video data from Finnish schools across several years and different grade levels, we realised a need to develop a systematic video coding and data visualisation method. In the following, we present a review on video research conducted in craft education and then describe our efforts to analyse and visualise longitudinal video data. Although emotions are important aspect in craft education, affecting the students' motivation to studies, it has proved out to be challenging to identify them by direct observation and video data analysis (Westerlund, 2015). The purpose of this article is to introduce our recent investigation of a video analysis method to code and visualise the emotional expressions of seventh-grade students' collaborative designing and making processes. This is an initial attempt to develop a method for identifying emotional expressions from the video data.

\section{Video research and data analysis in craft education}

Craft studies involve a large number of interactions, which is also revealed in the previous studies (Illum \& Johansson, 2012). Johansson (2002) performed video ethnography and microanalyses already in the late 1990s and published a methodological article based on three craft studies (Johansson, 2011). In addition, the sociocultural approach toward learning craft skills has highlighted social interactions and embodied connections to materials and tools (Ekström, 2012; Illum \& Johansson, 2012). Illum and Johansson (2012) used video-recorded data to show how communication in metal craft work took place in the form of verbal and nonverbal interactions (bodily positions, gestures and mimicries). Andersson and Johansson's (2017) conducted microanalysis on video data to reveal how the so called practical knowledge requires support from various multimodal forms of interactions. Further, Johansson and Lindberg (2017) initiated discussions on how to identify the learning of crafts and how differences in knowledge can be indicated in craft practices. Their study focused on the differences in craft knowledge between elementary students and more competent students in upper secondary school (Johansson \& Lindberg, 2017); the authors explicated how a specific knowledge content is built on the students' previous experiences. The analytic method was the ethnographic observation of events, which enabled the authors to provide a thick description of the selected events with the material artefacts used while working.

In the case of videotaped data, seeing classroom situations from every participant's perspective is challenging; thus, it is important to understand that every recorded video session is a result of careful selection. For example, Ekström and colleagues (2009) conducted a detailed analysis of an instructional 
sequence of learning new craft practices, namely of two distinct types of embroideries. The data were part of a project where over 75 hours of data were collected. However, the video analysis focused only on the distinctive differences between the activities of listening to instructions as part of a lecture and listening to instructions to be able to accomplish a task. Koskinen et al (2015) conducted a video study that was inspired by ethnomethodology (Goodwin, 2000; Knoblauch et al., 2009). The five hours of video data were collected during two weeks of student work on constructing garments. The focus of this study was on teacher-student embodied interactions, which were detected by gestures, facial expressions and body postures and movements, as well as the speech. For in-depth analyses of the teacher and students' embodied interactions, the content log of the entire video data was first produced, and for the deeper analysis, all episodes that represented the students' and teacher's embodied activities were selected. Based on Wagner-Willi (2006), the analysis distinguished three aspects of activity: social situation, interaction and subjects' actions.

Making craft objects in the classroom most often spans several lessons and contains, among other things, various sociomaterial aspects of working. In learning science research (Ash, 2007; Derry et al., 2010), different multivocality analysis methods have been conducted. Various data visualisation techniques have been used for tracing how learning activities and discourses unfold over time. These have provided visual aids for interpreting complex patterns of interaction (Hmelo-Silver et al., 2011). For example, chronologically oriented representations of discourse and tool-related activity CORDTRA diagrams, as well as the 'timeline graphs' of the INTERACT video analysis programme, can provide a multimodal and temporal account of the interrelations among verbal, gestural acts, representations and usage of tools (Hmelo-Silver et al., 2008; Hmelo-Silver et al., 2011).

In the study by Kangas et al (2013), CORDTRA diagrams were used for opening up the students' lamp design process and for providing a means to analyse the complex and iterative process in a structured manner. For the analysis, Ash's (2007) methodology of three levels - macro, intermediate and microof analysis for tracking meaning making in action was applied. To track the overall view of the project, videos were divided into five-minute units, and the main focus of the activity in each unit was defined as follows: 1) ideation, 2) elaborating ideas, 3) defining constraints, 4) making drawings, 5) constructing the model, 6) making a poster, 7) process organising or 8) off-topic activity. Based on this identification, a flow chart of the lamp designing sessions was created, showing the team's major design activities, as well as the time they used per session. The intermediate level of analysis focused on selecting significant events from the flow chart; here, the selected events provided representative slices of time (see Ash, 2007) from different phases of the project, exemplifying various kinds of activities. These selected events were analysed at the micro-level, where CORTDRA diagrams for pupils' material and social interactions were applied. Another study by Viilo et al (2018) analysed extensive video data of teacher's long-term orchestration and scaffolding process by using CORTDRA diagrams.

An inductive approach for data analysis begins by considering the entire corpus and then progressively zooming into select parts. We have developed and used various kinds of flow charts to understand the major activities in collaborative design and making processes. Usually, the first level of analysis provides a macro-level understanding of the teams' design processes (Lahti et al., 2016). A graphical timeline graph renders many patterns in the data visible so that they can be systematically tracked. This process requires developing a systematic coding system. Further, the micro-level analysis of activities requires zooming into the actions or events, requiring more fine-grained systematic categorisation of the events. In the study by Härkki et al (2018a), all micro-level events of sketching and note-writing were incorporated together (inscribing), creating links between them and neighbouring turns-at-talk that provided a very detailed picture of the sketching practices central for advancing collaborative designing. The other study (Härkki et al., 2018b) focused on the relationship between sketching and gestures during collaborative designing. In both studies, the INTERACT video analysis programme for tracking these forms of inscribing was used: it provided the ability to watch a video frame by frame because some events such as gesturing $\mathrm{s}$ could be as short as 0.2 seconds. The possibility to watch the running video, transcripts and annotations simultaneously through one main window enabled a more holistic analysis. 
The current article looks more closely at the longitudinal video data that focused on maker-centred learning projects. Maker-centred learning involves the utilisation of diverse traditional and digital tools and resources that vary across heterogeneous projects. The collaborative making project is seen as 1) multimaterial; 2) digitally enhanced; and 3) holistic in terms of including all stages of creation, from design ideation to experimentation and from fabrication to the evaluation of the final productions. However, there are methodological challenges regarding studying maker-centred learning because making happens 'around' digital technologies.

In the current article, we focus on an analysis method that we developed to identify the students' emotions during the collaborative designing and making process. We are aware that art and craft education can evoke emotions that are sometimes very strong (Casian et al., 2018; Ojala et al., 2018; Westerlund, 2015). Even after a long time, people have strong feelings about their failures and successes, as well as memories, about how it was to work in crafting contexts (Kokko, 2012). Because tools for detecting emotions during the craft process and from video data are lacking, we made an effort to develop them. The aim of the study is to introduce the systematic three-level video analysis method that was used for tracing the emotional aspects of a collaborative design and making process. Our main question was as follows: How can we identify students' emotions in the video data during a collaborative design and making process?

\section{Research setting and acquisition of the video data}

The present study is part of a larger research project (Growing Mind; see https://growingmind.fi/), where the aim was to develop maker-centred learning in Finnish elementary and secondary schools. The participating teachers and researchers together developed co-invention projects, where the students worked collaboratively to design and make complex artefacts involving both digital and material components. The data for the present study were collected from a technology-focused lower secondary school located in the capital area of Finland; data collection took place in the spring of 2018. A seventhgrade class comprising 18 students (aged 13 to 14) and four teachers (two craft teachers, a visual art teacher and an information and computer technology, i.e., ICT-teacher) participated in the project. Moreover, eighth-grade student tutors provided additional support to the participating student teams in the use of digital technologies.

In the present study, five heterogeneous student teams were formed, each team consisting of three to four members. The design task for the teams was an open-ended co-invention challenge: 'Invent a smart product or a smart garment by relying on traditional and digital fabrication technologies'. The project was initiated in February and involved eight weekly collaborative making sessions, roughly 90 minutes each over a period of three months. The teams also documented their progress in a digital portfolio. The teams organised their processes independently, seeking assistance from the teachers or tutors when needed.

The data were acquired through ethnographic video research (see Derry et al., 2010). The activities of each team were video recorded using an individual GoPro action camcorder and a wireless lavalier microphone to document team discussions. The camera was placed on a floor-standing tripod positioned at a high side angle to capture the team's actions as fully as possible. One researcher was present during every session to observe and write field notes in support of the analysis of the data. In addition, we collected the sketches and documents created by the teams and photographed the teams' co-inventions and their prototypes. When selecting a team for the present study, we wanted to concentrate on a team, which, according to the researcher's initial observations, was showing strong emotions. This team consisted of two girls and two boys, and their invention was called 'the Banana Light', that is, a bananashaped bending light that attaches to the laptop screen and lights the keyboard (Figure 1). Their whole 
co-invention process was video recorded, resulting in 11 hours of video data. The data were rich and dense, comprising verbal and materially embodied activities often expressed with emotions.
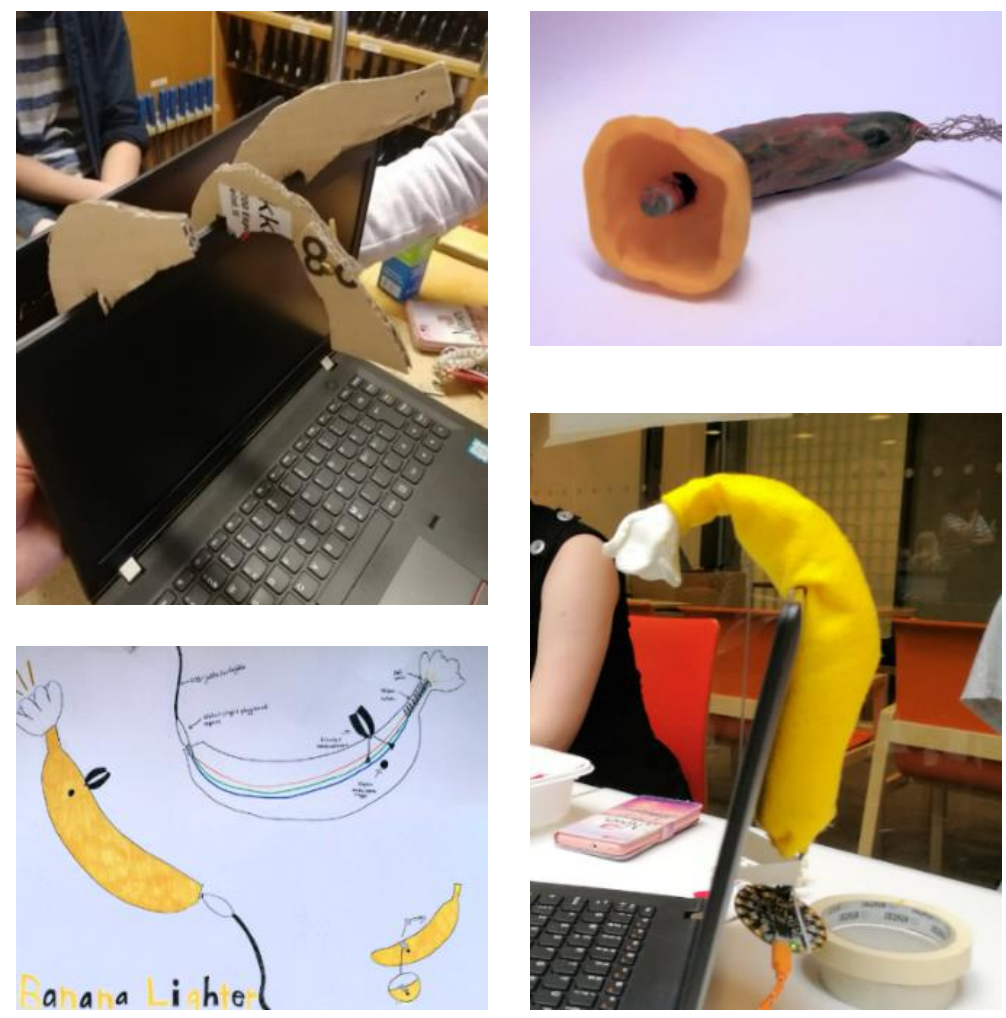

Figure 1. Drawings and mock-ups of the "Banana Light" invention

\section{The video data analysis method for identifying emotions}

During the research project, we further developed the systematic, three-level method (see Ash, 2007) for analysing the classroom video data of collaborative making processes. The method aims at revealing both the macro-level patterns of collaborative making process and enabling the micro-level examination of the selected episodes in accordance with the research questions. The general analytical process and how it was used to identify the emotions in the video data are presented in Table 1.

At the macro-level, we created the visual Making-Process-Rug, which illustrates the verbal and embodied design and making activities of the student team. The method was first published by Riikonen et al (2020) and we have also adapted this method in studies by Yrjönsuuri et al (2019) and Mehto et al (2020). At the intermediate level, we selected significant events representing various emotional expressions of the students. These events were further analysed at the micro-level, focusing on a detailed analysis of the emotional expressions and emotion clusters.

Table 1. Three levels of video analysis

\begin{tabular}{|l|l|l|}
\hline Level & Focus & Data \\
\hline Macro-level & $\begin{array}{l}\text { Making-Process-Rug of the verbal and } \\
\text { embodied design and making activities }\end{array}$ & $\begin{array}{l}11 \text { hours of video data divided in } \\
\text { three-minute segments }\end{array}$ \\
\hline Intermediate level & $\begin{array}{l}\text { Selecting significant events representing } \\
\text { various emotional expressions }\end{array}$ & $\begin{array}{l}28 \text { three-minute segments, } \\
\text { including emotional expressions }\end{array}$ \\
\hline Micro-level & $\begin{array}{l}\text { Identification of emotions and emotion } \\
\text { clusters }\end{array}$ & $\begin{array}{l}\text { Transcripts of verbal, embodied and } \\
\text { emotional actions }\end{array}$ \\
\hline
\end{tabular}




\section{Macro-level of analysis: Making-Process-Rug}

The macro-level analysis provides an overall understanding of the teams' design and making process, as well as ensuring a systematic means by which to review the data. The analysis involved two stages: 1) systematic coding of the video data and 2) conversion of these data into a visual form, which enabled us to perceive the patterns of collaborative making processes and their flow as a whole. When completed, the analysis produced colour-coded, layered diagrams that we refer to as Making-Process-Rugs because of their resemblance to woven rugs (Figure 2). This macro-level analysis was conducted by two independent investigators, ensuring the reliability of the coding procedure. At first, all segments containing no action were removed from the video data; these included double recordings, videos from an empty classroom and students working outside the camera's view. The final analysable data set consisted of 11 hours of video recordings (out of a total of approximately 14 hours of recordings).

We divided the whole video data in three-minute segments and coded the students' primary verbal and embodied design and making activities in each segment with the ELAN multimedia annotator (4.9.4 and 5.0.0-beta). We ended up using three-minute segmentation based on our experiences of earlier video studies and previous research on creative designing and making (Lahti et al, 2016). The resolution of the analysis unit is sufficient for revealing various design and making activities and their iterations; simultaneously, it is not too detailed for the first stage of the analysis. The categories were based on our earlier experiences of investigating maker-centred learning (e.g., Riikonen et al., 2020).

The primary verbal actions were related to the themes of a team's discourse and interaction, which included for example ideating and refining invention ideas, seeking information and discussing about manufacturing and process organising. The embodied making actions, in turn, involved using digital or traditional tools and materials for sketching, making prototypes, experimenting with mechanical or digital solutions and making presentation material. The codes within each of the primary categories were mutually exclusive so that the segment could represent only certain primary verbal or embodied action. Yet the coding system allowed identifying co-occurrences of verbal and embodied actions. By using fixed segmentation and systematic coding system, the method also enables determining the quantitative aspects of the collaborative making (e.g., relative proportion of certain types of verbal or embodied making actions); however, a quantitative data analysis is left out from the present study (see Riikonen et al, 2020).

Figure 2 presents the team's entire process, which is segmented into three-minute intervals. The MakingProcess-Rug is divided into three parts due to the limited space. The rug on the left illustrates the beginning of the process, where the main focus was on ideation. The middle rug represents the midprocess, which included various activities, such as digital experimenting, analysis, evaluation, and model making. The rug on the right depicts the end phase, during which the students continued making the model and prepared a poster for presenting their invention. The primary verbal and embodied actions were determined in each segment for the whole team (T) and each participant (1-4). When both verbal and embodied actions occurred simultaneously, the verbal action $(\mathrm{V})$ is presented on the left side of the segment and the embodied action (E) on the right. When the students divided their work into subtasks, the column representing the whole team $(\mathrm{T})$ is grey, and the individual students' activities are illustrated in their own columns (1-4). In addition, the segments revealing clear emotional expressions (Em) are identified with red stripes. The white areas with black borders indicate that one or more students were working outside the camera's view for a while, while the larger white area at the beginning of the process indicates that student 4 was absent during that time. 


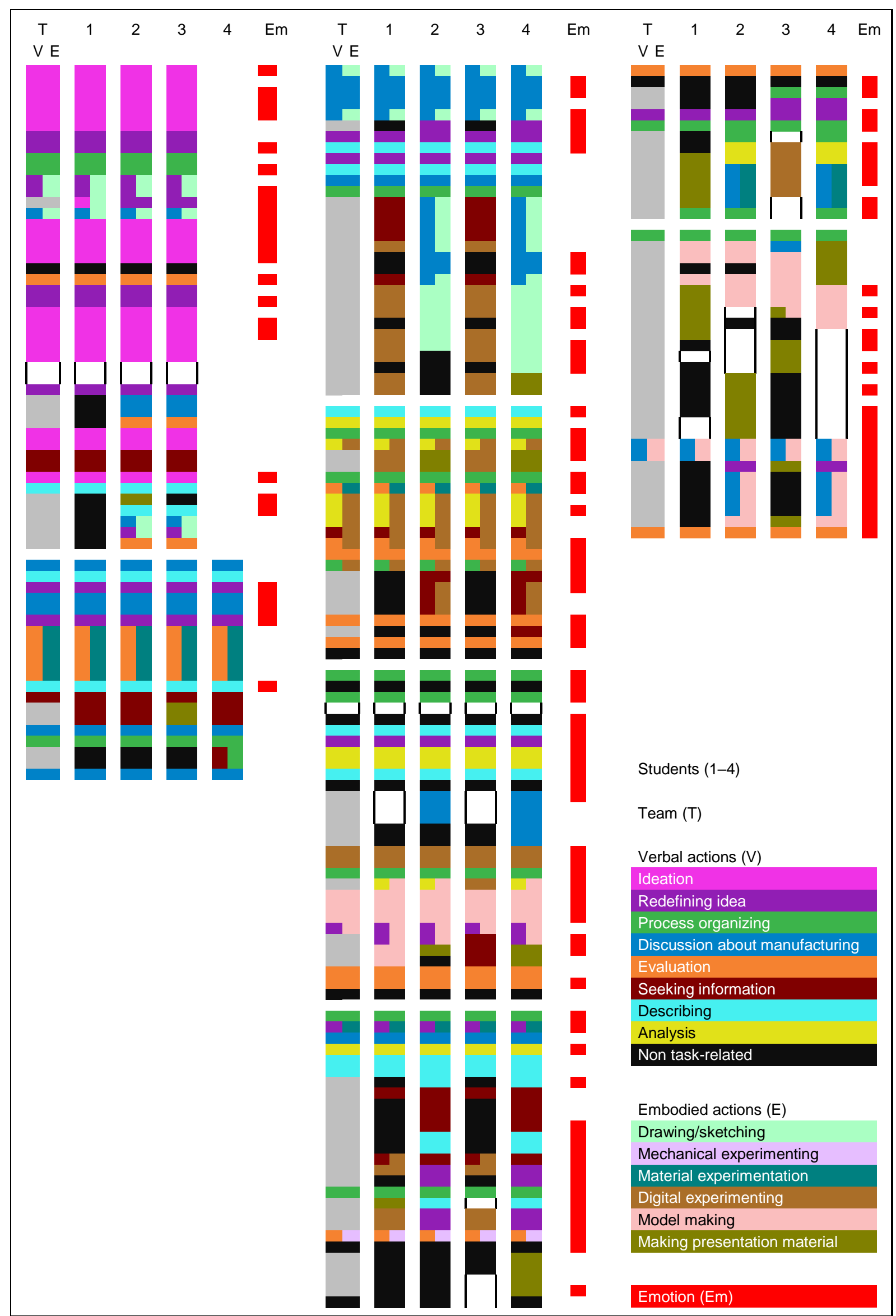

Figure 2. The Making-Process-Rugs of the verbal and embodied design and making activities during the co-invention process 
The Making-Process-Rug revealed the general pattern of the teams' designing and making process. The process began with intensive ideation (pink) of the smart product, followed by extensive discussion of manufacturing the design idea (blue) and sketching (light green), material experimentation and evaluation (orange), digital experimentation (brown), and information seeking (dark brown). In the middle of the process, the students created and evaluated mock-ups (beige) and then experimented with materials and mechanisms (lilac). Later, they developed coding for the microcontroller, produced the final "Banana Light" and prepared presentation materials. From time to time, the students organised their process and divided the tasks; for example, some students concentrated on making the model, while others were concentrated on the presentation materials.

\section{Intermediate level of analysis: Selecting representative examples of emotional expressions}

The Making-Process-Rug shows that there were emotions involved in many of the activities and different phases (red). Our next step was the intermediate level of analysis, where we zoomed into the segments where clear emotional expressions were present. Some of these were selected for further analysis. The criteria for selection were the following: a) the segments provided representative examples of various emotional expressions; $b$ ) the segments were related to various activities from differing phases of the process; and c) the quality of the video data enabled a very fine-grained analysis of emotional expressions (e.g., the students' face was in a good angle towards the camera).

At first, we identified 22 segments that met the criteria from various phases of the process, for example, ideation, discussing about manufacturing and digital experimenting (Table 2). In addition, the MakingProcess-Rug revealed a recurring connection between one verbal activity and emotional expression; process organising (green stripes in Figure 2) evoked students' emotions almost without exception. Consequently, in the analysis, we decided to include the six segments where process organising and emotional expressions were present simultaneously. Thus, altogether, 28 segments with emotional expressions were selected for further analysis.

Table 2. The 28 emotional expressions selected for further analysis

\begin{tabular}{|c|c|c|c|}
\hline Session & \multicolumn{2}{|c|}{ Verbal and/or embodied actions } & $\begin{array}{l}\text { Number of } \\
\text { emotional }\end{array}$ \\
\hline \multirow[t]{7}{*}{6} & Ideation & & 1 \\
\hline & & & 2 \\
\hline & & & 3 \\
\hline & & & 4 \\
\hline & & & 5 \\
\hline & & & 6 \\
\hline & Process organising & & 7 \\
\hline \multirow[t]{6}{*}{8} & \multirow[t]{4}{*}{ Discussion about manufacturing } & & 8 \\
\hline & & Drawing/sketching & 9 \\
\hline & & & 10 \\
\hline & & & 11 \\
\hline & \multirow[t]{2}{*}{ Digital experimenting } & & 12 \\
\hline & & & 13 \\
\hline \multirow[t]{4}{*}{9} & Analysis & \multirow[t]{4}{*}{ Digital experimenting } & 14 \\
\hline & Evaluation & & 15 \\
\hline & Process organising & & 16 \\
\hline & & & 17 \\
\hline \multirow[t]{3}{*}{10} & Model making & & 18 \\
\hline & & & 19 \\
\hline & Process organising & & 20 \\
\hline \multirow[t]{2}{*}{11} & Process organising & & 21 \\
\hline & & & 22 \\
\hline \multirow[t]{2}{*}{12} & Discussion about manufacturing & Material experimentation & 23 \\
\hline & & & 24 \\
\hline \multirow[t]{4}{*}{13} & Making presentation material & & 25 \\
\hline & & & 26 \\
\hline & Discussion about manufacturing & Model making & 27 \\
\hline & & & 28 \\
\hline
\end{tabular}




\section{Micro-level of analysis: Identification of emotions and emotion clusters}

At the micro-level analysis of emotions, we leaned on research where the expression of emotions has been examined from an embodied perspective as a combination of several gestures and movements (Keltner et al., 2019; Witkower \& Tracy, 2019; Wallbott, 1998). These studies have revealed that certain embodied activities relate to specific emotions (see also Ekman, 2004). Based on these studies, we created a coding schema where typical bodily gestures and movements were connected to certain basic emotions (pride, joy, sadness, shame, fear, confusion, anger, disgust, etc.). We continued by categorising the gestures and movements in the main and subcategories and focused on each part of the body with typical gestures and movements to express a certain emotion. The categorisation concerned movements of the whole body and variations of the positions of the upper body, chest and shoulders. In addition, movements of the head, hands and fingers, as well as facial expressions, were included. For example, the main category 'torso' was divided into the subcategories of torso, chest and shoulders, and the main category 'face' into the subcategories of face, mouth, nose, eyebrows, jaw, lips and eyes. Each subcategory was further divided into several smaller subgroups; for instance, the subcategory 'shoulders' included seven various movements and gestures, such as shoulders back or shoulders slumped. Similarly, the subcategory 'mouth' consisted of 10 subgroups, such as mouth open or lip corners depressed.

The selected 28 segments were analysed according to the coding schema. The unit of analysis was now the emotional expressions (1-13 seconds) of one student. The emotional expressions were examined and annotated using a coding schema with descriptive codes, words or phrases. We analysed the expressions as emotion clusters, that is, as combinations of gestures, facial expressions, body postures and movements because research has revealed that the identification of emotions is more precise when two or more emotional expressions are examined as a cluster (Gunes \& Piccardi, 2007; Knapp \& Hall, 2010). An example of analysing how a student expressed the basic feeling of joy with an emotion cluster is visualised in Figure 3. The student leaned forward and turned away from another student, who was speaking. Her face showed a duchenne display, a genuine smile where the corners of her mouth were pulled back and her eyes slightly tightened (see Plutchik, 2003). The student laughed and covered her mouth with her left hand.

$\begin{array}{ll}\text { TORSO } & \text { Turning away } \\ \text { FACE } & \text { Duchenne display } \\ \text { Mouth } & \text { Corners of mouth pulled back } \\ \text { Eyes } & \text { Eyes slightly tightened } \\ \text { ARMS } & \text { Arm movement in front of body } \\ \text { Hands } & \text { Hands covering or touching face } \\ \text { Note! } & \text { Hand covers mouth } \\ \text { SOUND } & \text { Student makes sound } \\ \text { Sound1 } & \text { 'Laugh' } \\ & \end{array}$

Figure 3. Emotion cluster expressing joy

Another example of an emotion cluster represents dramatized sadness (Figure 4). The student had put on computer music that reflected sadness. He leaned forward, his upper body collapsed, and his shoulders slumped. Both of his arms were in front of his body, and his hands were covering his face. His whole body was shaking and the student pretended that he was crying. In addition, he said, 'Lost my motivation'. 


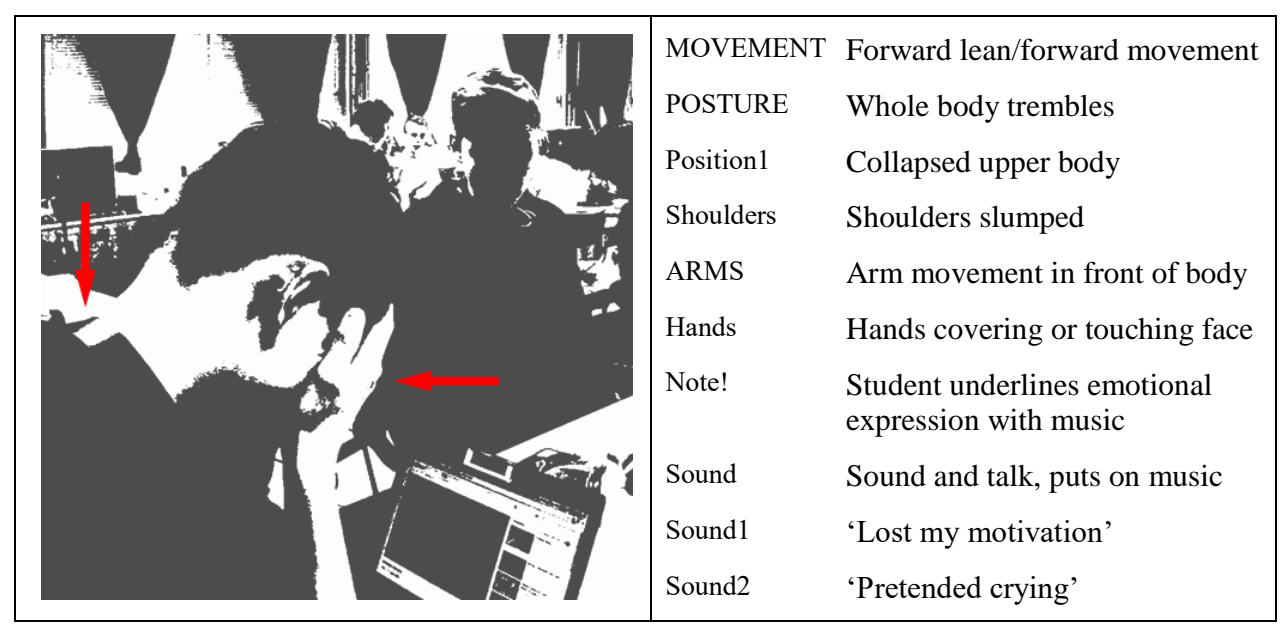

Figure 4. Emotion cluster expressing dramatized sadness.

\section{Some observations of the findings}

The study revealed various emotions in different phases of the maker project. The small number of students in one craft education context does not allow us to draw wider conclusions, therefore, we introduce only some observations from the findings (Table 3). These observations may serve as examples of the way the created method could serve in identifying the students' emotions in craft and even other fields of studies.

Table 3. Students' emotions during the design and making process

\begin{tabular}{|c|c|c|c|c|}
\hline Session & \multicolumn{2}{|c|}{ Verbal and/or embodied actions } & \multicolumn{2}{|c|}{ Students' emotions } \\
\hline \multirow[t]{2}{*}{6} & \multicolumn{2}{|l|}{ Ideation } & $\begin{array}{l}1 \\
2 \\
3 \\
4 \\
5 \\
6\end{array}$ & joy \\
\hline & Process organising & & 7 & disgust and indifference \\
\hline \multirow[t]{4}{*}{8} & \multirow{3}{*}{$\begin{array}{l}\text { Discussion about } \\
\text { manufacturing }\end{array}$} & & 8 & anger \\
\hline & & Drawing/sketching & 9 & \multirow{2}{*}{$\begin{array}{l}\text { astonishment and insight } \\
\text { anger and frustration }\end{array}$} \\
\hline & & & $\begin{array}{l}10 \\
11\end{array}$ & \\
\hline & Digital experimenting & & $\begin{array}{l}12 \\
13\end{array}$ & 'sadness' and failure \\
\hline \multirow[t]{3}{*}{9} & Analysis & Digital experimenting & \multirow{3}{*}{$\begin{array}{l}14 \\
15 \\
16 \\
17\end{array}$} & anger \\
\hline & Evaluation & & & joy \\
\hline & Process organising & & & anger \\
\hline \multirow[t]{2}{*}{10} & Model making & & $\begin{array}{l}18 \\
19\end{array}$ & joy \\
\hline & Process organising & & 20 & anger \\
\hline 11 & Process organising & & $\begin{array}{l}21 \\
22 \\
\end{array}$ & anger \\
\hline 12 & $\begin{array}{l}\text { Discussion about } \\
\text { manufacturing }\end{array}$ & Material experimentation & $\begin{array}{l}23 \\
24\end{array}$ & $\begin{array}{c}\text { disgust } \\
\text { anger and frustration }\end{array}$ \\
\hline \multirow[t]{2}{*}{13} & $\begin{array}{l}\text { Making presentation } \\
\text { material }\end{array}$ & & $\begin{array}{l}25 \\
26\end{array}$ & anger \\
\hline & $\begin{array}{l}\text { Discussion about } \\
\text { manufacturing }\end{array}$ & Model making & $\begin{array}{l}27 \\
28\end{array}$ & joy \\
\hline
\end{tabular}


First, the iterative nature of the team's design process became evident from the Making-Process-Rugs. Second, among this group of students, there were clear differences in the nature of emotions they expressed in different phases of the process. Here, the ideation in the beginning of the craft process was reflected in expressions of joy. Having fun, laughing and telling jokes was visible both in their verbal and bodily actions. Quite the contrary, the mid-phase discussions about manufacturing and material experimentation caused anger and frustration. Digital experimenting was first related to the feelings of failure, 'sadness' (dramatized) and even anger, but in the end, the students expressed joy of their successful experiments. The actual making of the model was reflected in expressions of joy, while making the presentation material about the project triggered anger. Process organising throughout the project caused anger and even feelings of disgust and indifference. At the end, the fully functioning final product, 'Banana Light', was met with joy.

\section{Discussion}

The purpose of the current study was to present the systematic, three-level video analysis method that was developed for tracing the emotional aspects of a collaborative design and making process. We analysed the emotional expressions of one Finnish seventh-grade student team during a maker-centred project, where they used both traditional and digital fabrication technologies. The study involved the development of Making-Process-Rug, which is used for a macro-level analysis and visual characterisation of the patterns of the whole process. The process consisted of the selection of significant events as representative examples of students' emotional expressions and zooming into a micro-level level analysis of the teams' emotions during collaborative processes. To get a comprehensive view of the longitudinal process, it was necessary to carry out the segmentation of the video data at a quite coarse level at first. The macro-level analysis enabled the revealing of the iterative nature of the process, as well the events of emotional expression. In turn, the micro-level analysis enabled a more refined analysis of students' emotion clusters in specific learning situations.

Heath et al. (2010; see also Derry et al., 2010) described three choices that the researcher has to make when pursuing videographic research: 1) find the action (i.e., which situations will be recorded), 2) avoid action (i.e., which situations will be excluded) and 3) frame the action (i.e., selection of the sample for further examination). However, when relying only on one video camera, the entire richness of a learning situation is difficult to capture. The visual representations of the temporal flow of process are needed for tracing and understanding collaborative processes, revealing who are actively participating, what the participants are actually doing and how participants' verbal and embodied actions are related to one another (Hmelo-Silver et al., 2008). The specific benefit of the Making-Process-Rug method is that it allows simultaneous tracing of social-discursive and materially embodied aspects of activities. It captures the sociomaterial entanglements of the making process (Mehto et al, 2020), such as how the conceptual and materially embodied aspects of knowledge creation interlink during the processes. The method enables analysing large samples of video data and comparing, for example, event sequences across different maker-centred projects when using similar coding systems. Further, the three-level method allows focusing on fine-grained micro-level of analysis without losing the overall macro-level perspective of the project. We believe that the Making-Process-Rug method can be a useful instrument for other investigators interested in multifaceted process analysis from video data.

The study presented in the current article presents our first attempt at developing an analysis method for detecting the emotions in the video data. Research has revealed the importance of emotions in efficient learning (Tyng et al., 2017; Westerlund, 2015), and there is lot of potential in developing the ways to analyse expressions of emotions in educational contexts. By detecting the emotions during the learning process, we were able to identify the phases in which emotional support would be the most valuable to enhance learning. Our first attempt for analysing emotions from video data was developed with a small student group. Obviously, there is need both to test and develop the method further in larger research settings. The culture-specific expressions and interpretations of emotions (Westerlund, 2015) require special attention when developing the method further. The analysis method introduced in the current 
article was developed in a craft education context, where embodied and material aspects are central. However, the method of video analysis and identification of emotions could benefit all spheres of education.

Acknowledgements This research was funded by the Academy of Finland [grant 286837], Strategic Research Council of the Academy of Finland [grant 312527] and Ministry of Education and Culture [grant OKM/100/592/2018].

\section{References}

Andersson, J. (2019). Instruktion av hantverkstekniker i slöjden - fiktiv och konkret handling som kommunikativ resurs. FormAkademisk, 12(1), 1-18. https://doi.org/10.7577/formakademisk.2761

Andersson, J. \& Johansson, M. (2017). Learning situations in Sloyd - to become more handy, dexterous and skillful. Techne Series: Research in Sloyd Education and Craft Science, 24(2), 93-109. https://doi.org/10.1007/978-3-319-74609-8 4

Ash, D. (2007). Using video data to capture discontinuous science meaning making in nonschool setting. In R. Goldman, R. Pea, B. Barron, \& S. J. Derry (Eds.), Video research in learning science (pp. 207-226). Mahvah, NJ: Erblaum.

Casian, S., Lopes, A., \& Pereira, F. (2018). (Re) thinking emotions in visual education activities: Students' experiences. International Journal of Art and Design Education, 37(3), 399-412. https://doi.org/10.1111/jade.12141

Carlsen, K. (2015). Forming i barnehagen i lys av Reggio Emilias atelierkultur (Akademisk avhandling vid Pedagogiska fakulteten). Vasa: Åbo Akademi University Press.

Derry, S. J., Pea, R. D., Barron, B., Engle, R. A., Erickson, F., Goldman, R., Hall, R., Koschmann, T., Lemke, J., Sherin, M., \& Sherin, B. L. (2010). Conducting video research in the learning sciences: Guidance on selection, analysis, technology, and ethics. Journal of the Learning Sciences, 19(1), 3-53 https://doi.org/10.1080/10508400903452884

Ekman, P. (2004). Emotions Revealed: Understanding Faces and Feelings. London: Phoenix. https://doi.org/10.1136/sbmj.0405184

Ekström, A., Lindwall, O., \& Säljö, R. (2009). Questions, instructions, and modes of listening in the joint production of guided action: A study of student-teacher collaboration in handicraft education. Scandinavian Journal of Educational Research, 53(5), 497-514. https://doi.org/10.1080/00313830903180794

Ekström, A. (2012). Instructional work in textile craft - Studies of interaction, embodiment and the making of objects. Stockholm University, Studies in education in arts and professions 3.

Goodwin, C. (2000). Action and embodiment within situated human interaction. Journal of Pragmatics, 32(10), 1489-1522. https://doi.org/10.1016/S0378-2166(99)00096-X

Groth, C., Mäkelä, M. and Seitamaa-Hakkarainen, P. (2015). Tactile augmentation: A multimethod for capturing experiential knowledge. Craft Research 6(1), 59-83. https://doi.org/10.1386/crre.6.1.57_1

Gunes, H., \& Piccardi, M. (2007). Bi-modal emotion recognition from expressive face and body gestures. Journal of Network and Computer Applications, 30(4), 1334-1345. https://doi.org/10.1016/j.jnca.2006.09.007

Heath, C., Hindmarsh, J., \& Luff, P. (2010). Video in qualitative research. Analysing social interaction in everyday life. Los Angeles, CA: SAGE. https://doi.org/10.4135/9781526435385

Hmelo-Silver, C. E., Chernobilsky, E., \& Jordan, R. (2008). Understanding collaborative learning processes in new learning environments. Instructional Science, 36, 409-430. https://doi.org/10.1007/s11251-008-9063-8

Hmelo-Silver, C. E., Jordan, R., Liu, L., \& Chernobilsky, E. (2011). Representational tools for understanding complex computer-supported collaborative learning environments. In S. Puntambekar, G. Erkens, \& C. Hmelo-Silver (Eds.), Analyzing interactions in CSCL. Methods, approaches, and issues (pp. 83-106). New York, NY: Springer.

Härkki, T, Hakkarainen, K \& Seitamaa-Hakkarainen, P (2018a). Line by line, part by part - collaborative sketching for designing. International Journal of Technology and Design Education, 28(2), 471-494. https://doi.org/10.1007/s10798-016-9379-7

Härkki, T, Seitamaa-Hakkarainen, P. \& Hakkarainen, K. (2018b). Hands on design: Comparing the use of sketching and gesturing in collaborative designing. Journal of Design Research, 16(1), 24-46. https://doi.org/10.1504/JDR.2018.10012264 
Illum, B., \& Johansson, M. (2012). Transforming physical materials into artefacts - Learning in the school's practice of sloyd. Techne Series: Research in Sloyd Education and Crafts Science, 19(1), 2-16.

Johansson, M. (2002). Slöjdpraktik i skolan - hand, tanke, kommunikation och andra medierande redskap (Göteborg Studies in Educational Science, 183). Göteborg: Acta Universitatis Gothoburgensis.

Johansson, M. (2011). Vad och hur gör de? [What and how you do it?] Techne Series: Research in Sloyd Education and Craft Science, 18(1), 33-48.

Johansson, M., \& Lindberg, V. (2017). Att lära sig se trådraken - om tvekan och fokusförskjutning på väg mot förändrat kunnande. Techne Series: Research in Sloyd Education and Craft Science, 24(1), 1-16.

Kangas, K. \& Seitamaa-Hakkarainen, P., \& Hakkarainen K. (2013). Design Thinking in Elementary Students' Collaborative Lamp Designing Process. Design and Technology: an International Journal, 18(1), 30-43

Keltner, D., Sauter, D., Tracy, J. \& Cowen, A. (2019). Emotional expression: Advances in basic emotion theory. Journal of Nonverbal Behavior, 43(2), 133-160. https://doi.org/10.1007/s10919-019-00293-3

Knapp, M. L., \& Hall, J. A. (2010). Nonverbal communication in human interaction. Boston Mass., South Melbourne: Wadsworth/Cengage Learning.

Knoblauch, H., Schettler, B., Raab, J., \& Soeffner, G. (Ed.). (2009). Video analysis: Methodology and methods. Qualitative audiovisual data analysis in sociology. Frankfurt am Main: Peter Lang.

Kokko, S., Almevik, G., Høgseth, H. B. and Seitamaa-Hakkarainen, P. (2020) Mapping the methodologies of the Craft Sciences in Finland, Sweden and Norway. Craft Research, 11(2), 177-209. https://doi.org/10.1386/crre_00025_1

Kokko, S. (2012). Learning crafts as practices of masculinity. Finnish male trainee teachers' reflections and experiences. Gender \& Education, 24(2), 177-193. https://doi.org/10.1080/09540253.2011.602331

Koskinen, A \& Seitamaa-Hakkarainen, P, Hakkarainen, K (2015). Interaction and embodiment in craft teaching. Techne Series: Research in Sloyd Education and Craft Science, 22(1), 59-72.

Lahti, H., Seitamaa-Hakkarainen, P, Kangas, K, Härkki, T \& Hakkarainen, K (2016). Textile teacher students' collaborative design processes in a design studio setting. Art, Design and Communication in Higher Education, 15(1), 35-54. https://doi.org/10.1386/adch.15.1.35_1

Mehto, V., Riikonen, S., Kangas, K., \& Seitamaa-Hakkarainen, P (2020). Sociomateriality of collaboration within a small team in secondary school maker-centered learning. International Journal of Child Computer Interaction, 26. https://doi.org/10.1016/j.ijcci.2020.100209

Ojala, M., Karppinen, S., \& Syrjäläinen, E. (2018). Towards making sense of self through emotional experiences in craft-art. Craft Research, 9(2), 201-227. https://doi.org/10.1386/crre.9.2.201_1

Plutchik, R. (2003). Emotions and life: Perspectives from psychology, biology, and evolution. Washington, DC: American Psychological Association.

Reimann, P. (2009). Time is precious: Variable and event-centered approaches to process analysis in CSCL research. International Journal of Computer-Supported Collaborative Learning, 4, 239-257. https://doi.org/10.1007/s11412-009-9070-z

Riikonen, S., Seitamaa-Hakkarainen, P \& Hakkarainen, K., (2020) Bringing maker practices to school: Tracing discursive and materially mediated aspects of student teams' collaborative making processes Student. Journal of Computer Supported Collaborative Learning, 15(3), 319-349. https://doi.org/10.1007/s11412$\underline{020-09330-6}$

Streeck, J. Goodwin, C., \& LeBaron, C. (2011). Embodied interaction in the material world: An introduction. In J. Streeck, C. Goodwin, \& C. LeBaron (Eds.), Embodied interaction. Language and body in the material world. Learning in doing: social, cognitive and computational perspectives (pp. 1-26). New York: Cambridge University Press.

Tyng, C. M., Amin, H. U., Saad, M. N. M., \& Malik, A. S. (2017). The influences of emotion on learning and memory. Frontiers in Psychology, 8, 1454-1454. https://doi.org/10.3389/fpsyg.2017.01454

Viilo M., Seitamaa-Hakkarainen, P. \& Hakkarainen K. (2018). Teacher's long-term orchestration of technologymediated collaborative inquiry project. Scandinavian Journal of Educational Research, 62(3), 407-432. https://doi.org/10.1080/00313831.2016.1258665

Wagner-Willi, M. (2006). On the multidimensional analysis of video-data: documentary interpretation of interaction in schools. In H. Knoblauch, B. Schnettler, J. Raab \& H-G. Soeffner (Eds.), Video analysis: Methodology and methods: Qualitative audiovisual data analysis in sociology (pp. 143-153). Frankfurt am Main: Peter Lang. 
Westerlund, S. (2015). Lust och olust - elevers erfarenheter i textilslöjd (Doktorsavhandlingar i Pedagogiskt arbete, 59). Umeå: Umeå universitet, Institutionen för estetiska ämnen.

Witkower, Z., \& Tracy, J. (2019). Bodily communication of emotion: Evidence for extra-facial behavioral expressions and available coding systems. Emotion Review, 11(2), 184-193. https://doi.org/10.1177/1754073917749880

Wallbott, H. G. (1998). Bodily expression of emotion. European Journal of Social Psychology, 28(6), 879-896. https://doi.org/10.1002/(SICI)1099-0992(1998110)28:6<879::AID-EJSP901>3.0.CO;2-W

Yliverronen, V, Marjanen, P. \& Seitamaa-Hakkarainen (2018). Peer Collaboration of six-year olds when undertaking a design task. Design and Technology: an international Journal, 23(2), 106-128.

Yrjönsuuri, V., Kangas, K., Hakkarainen, K. \& Seitamaa-Hakkarainen, P (2019). The roles of material prototyping in collaborative design process at an elementary school. Design and Technology Education: an international journal, 24(2), 141-162.

Tiina Paavola (M.Ed.) is a craft teacher at a primary school. Her teaching is combining the working methods of both technical and textile crafts.

Kaiju Kangas (Ph.D.) is an assistant professor of Technology Education at the University of Helsinki. Her research focuses on the design and implementation of maker-centered learning at pre-primary and comprehensive levels of education, as well as in pre- and in-service teacher education.

Sirpa Kokko (Ph.D.) is a University Lecturer at the University of Helsinki. Her research interests concern arts and crafts in the culture and society as well as in education both in Finland and in international contexts.

Sini Riikonen (M. Ed.) is a doctoral student in Craft Science and Technology Education at the University of Helsinki. Her research interests focus on maker-centered, technology-enhanced, collaborative knowledge creation processes and learning in k12-education, as well as in teacher education.

Varpu Mehto (M.Ed.) is a doctoral student at the University of Helsinki, Faculty of Educational Sciences. Her research interests focus on sociomateriality and embodiment in collaborative design and innovation processes.

Kai Hakkarainen (Ph.D.) is a professor of Education at the University of Helsinki. His research deals with technology-enhanced, creative and collaborative learning from primary school to higher education.

Pirita Seitamaa-Hakkarainen (Ph.D.) is a professor of Craft Science at the University of Helsinki. Her research interests focus on design processes and facilitation of collaborative design through technologyenhanced learning. 